\title{
Toxicity of Zn-Fe Layered Double Hydroxide to Different Organisms in the Aquatic Environment
}

\author{
Olga Koba-Ucun ${ }^{1}$, Tuğba Ölmez Hanci ${ }^{1}$, Idil Arslan-Alaton ${ }^{1, *}$, Samira Arefi-Oskoui ${ }^{2}$, Alireza Khataee ${ }^{2,3, *(D),}$ \\ Mehmet Kobya ${ }^{3,4}$ and Yasin Orooji ${ }^{5}$ (D)
}

1 Department of Environmental Engineering, School of Civil Engineering, Istanbul Technical University, 34469 Maslak, Istanbul, Turkey; kobaucun@itu.edu.tr (O.K.-U.); tolmez@itu.edu.tr (T.Ö.H.)

2 Research Laboratory of Advanced Water and Wastewater Treatment Processes, Department of Applied Chemistry, Faculty of Chemistry, University of Tabriz, Tabriz 51666-16471, Iran; s.arefi@tabrizu.ac.ir

3 Department of Environmental Engineering, Gebze Technical University, 41400 Kocaeli, Gebze, Turkey; kobya@gtu.edu.tr

4 Department of Environmental Engineering, Kyrgyz-Turkish Manas University, Bishkek 720038, Kyrgyzstan

5 College of Materials Science and Engineering, Nanjing Forestry University, Nanjing 210037, China; yasin@njfu.edu.cn

* Correspondence: arslanid@itu.edu.tr (I.A.-A.); akhataee@gtu.edu.tr (A.K.)

\section{check for}

updates

Citation: Koba-Ucun, O.; Ölmez Hanci, T.; Arslan-Alaton, I.; Arefi-Oskoui, S.; Khataee, A.; Kobya, M.; Orooji, Y. Toxicity of Zn-Fe Layered Double Hydroxide to Different Organisms in the Aquatic Environment. Molecules 2021, 26, 395 https://doi.org/10.3390/ molecules26020395

Academic Editor: Giancarlo Cravotto Received: 29 November 2020 Accepted: 6 January 2021 Published: 13 January 2021

Publisher's Note: MDPI stays neutral with regard to jurisdictional clai$\mathrm{ms}$ in published maps and institutional affiliations.

Copyright: $\odot 2021$ by the authors. Licensee MDPI, Basel, Switzerland. This article is an open access article distributed under the terms and conditions of the Creative Commons Attribution (CC BY) license (https:// creativecommons.org/licenses/by/ $4.0 /)$.

\begin{abstract}
The application of layered double hydroxide (LDH) nanomaterials as catalysts has attracted great interest due to their unique structural features. It also triggered the need to study their fate and behavior in the aquatic environment. In the present study, Zn-Fe nanolayered double hydroxides ( $\mathrm{Zn}$ Fe LDHs) were synthesized using a co-precipitation method and characterized by X-ray diffraction (XRD), Fourier transform infrared spectroscopy (FT-IR), scanning electron microscopy (SEM), and nitrogen adsorption-desorption analyses. The toxicity of the home-made Zn-Fe LDHs catalyst was examined by employing a variety of aquatic organisms from different trophic levels, namely the marine photobacterium Vibrio fischeri, the freshwater microalga Pseudokirchneriella subcapitata, the freshwater crustacean Daphnia magna, and the duckweed Spirodela polyrhiza. From the experimental results, it was evident that the acute toxicity of the catalyst depended on the exposure time and type of selected test organism. Zn-Fe LDHs toxicity was also affected by its physical state in suspension, chemical composition, as well as interaction with the bioassay test medium.
\end{abstract}

Keywords: layered double hydroxide (LDH) catalysts; Pseudokirchneriella subcapitata; Daphnia magna; Spirodela polyrhiza; Vibrio fischeri; surface analysis; bioassays

\section{Introduction}

Recently, layered double hydroxides (LDHs) which are two-dimensional structured anionic clay materials, have attracted interest in various engineering fields [1]. LDHs are a type of engineered nanomaterial (NM) generally represented by the formula " $\left[\mathrm{M}^{2+}{ }_{1-x} \mathrm{M}^{3+} \mathrm{x}\right.$ $\left.(\mathrm{OH})_{2}\right]^{\mathrm{x}+}\left(\mathrm{A}^{\mathrm{n}-}\right)_{\mathrm{x} / \mathrm{n}} \cdot \mathrm{mH}_{2} \mathrm{O}^{\prime \prime}$, where $\mathrm{M}^{2+}$ stands for the divalent cation, $\mathrm{M}^{3+}$ for the trivalent cation, and $\mathrm{A}^{\mathrm{n}-}$ for the interlayer anion [2-6]. Their high specific surface area, catalytic ability, anion exchange capability, thermal stability, tunability, as well as flexibility in their interlayer spaces [2,7] render them high performance and unique materials. Hence LDHs found their applications in various fields such as biology $[1,6]$, electrochemistry $[6,8,9]$, photochemistry $[10,11]$, pharmacy and medicine $[1,12]$. They are also used as additives in polymers, adsorbents in water purification systems [13] and, in particular, as catalytic nanomaterials or catalyst supports [10,14-17]. Additionally, LDHs reduce catalyst leaching by keeping the $\mathrm{pH}$ at alkaline conditions. Owing to their low cost, sustainability, high catalytic activity, power, absorbing nature, and chemical stability LDHs have proven to be suitable materials for environmental remediation applications $[18,19]$. For instance, $\mathrm{Zn}-\mathrm{Fe} \mathrm{LDHs}$ was reported to have efficient adsorption capacity (equilibrium adsorption $=74.50 \mathrm{mg} / \mathrm{g}$ ) 
for diclofenac from aqueous solution [13], while a graphene oxide/Mg-Fe-LDHs composite exhibited high adsorption capacity for heavy metal ions including $\mathrm{Pb}(\mathrm{II}), \mathrm{Cd}(\mathrm{II}), \mathrm{Cu}(\mathrm{II})$, and $\mathrm{Zn}$ (II) [20]. Zn-Fe bifunctional materials were successfully used in the simultaneous removal of pharmaceuticals and arsenic through photochemical oxidation and adsorption from water [21]. Multi-metal Cu-Zn-Fe-LDHs materials were applied in water treatment as heterogeneous Fenton-like oxidation catalysts and adsorbents for acetaminophen and arsenic [22]. It was also reported that $\mathrm{Cu}-\mathrm{Mg}-\mathrm{Fe} \mathrm{LDHs}$ exhibited excellent performance for the degradation of ethylbenzene by persulfate activation [23]. In a study by Zhao et al. (2018), Co-Mn LDHs showed excellent performance in organic dye removal via peroxymonosulfate activation [24]. The thermal stability and antibacterial activity against some clinically important bacterial pathogens, namely Bacillus subtilis, Pseudomonas aeruginosa, Staphylococcus aureus, and Escherichia coli was proven for a polyacrylonitrile/Zn-Al LDHs nanocomposite $[25,26]$. Wang et al. (2018) prepared various types of lysozyme modified LDHs which exhibited excellent antibacterial activity and wound healing ability [27].

Despite the above mentioned exciting and promising applications of LDHs, their potential adverse effects require further investigation. There are some basic mechanisms by which NMs such as LDHs may elicit potential toxicity, namely direct interaction with the cell surface, dissolution of toxic elements from nanoparticles, and production of reactive oxygen species (ROS) causing oxidative stress [28,29]. Hence, the selection of appropriate toxicity tests and test organisms are critical issues to obtain reliable and sensitive results in ecotoxicological studies [30,31]. In particular, the use of organisms from different trophic levels is highly recommended to follow-up toxic effects and associated health risks in the form of battery tests [32]. Among the available toxicity tests, the Vibrio fischeri (V. fischeri) bioluminescence inhibition assay is frequently chosen due to its high reproducibility, speed, and sensitivity towards a wide range of pollutants [33]. On the other hand, green algae are primary producers and key indicators of the environmental balance in aquatic ecosystems. Growth inhibition tests employing unicellular algae are very common and routinely used to determine the toxicity of a variety of pollutants. Among these algal test species, the freshwater microalgae Pseudokirchneriella subcapitata (P. subcapitata; previously known as Selenastrum capricornutum) was found to be the most sensitive one for ecotoxicological studies [34]. Similarly, Daphnia magna (D. magna) being one of the freshwater crustaceans/invertebrates, have also been defined as routine and standard tools of toxicity test protocols [35-37]. They have been used in preliminary screening tests for evaluating the lethal toxicity of different (mainly industrial) chemicals to mammals and humans [38]. Moreover, the toxicity response of higher plants is extremely helpful in monitoring the environmental impact of contaminants [39]. Hence, the Lemna bioassay, also known as the duckweed test, is one of the most common, standardized test procedures for ecotoxicological studies involving higher plants [40]. Herein, species from the genus Lemna, monocotyledonous free-floating aquatic macrophytes from the Lemnaceae family are routinely used [40]. Last but not least, algal, daphnid, and Lemna tests are all Organisation for Economic Co-operation and Development (OECD) assays as well as legislator tests, for example, Registration, Evaluation, Authorization, and Restriction of Chemicals (REACH) [40]. For all of these reasons, the above-mentioned test organisms were employed in the present study.

Although a variety of physicochemical properties of novel NMs have already been investigated by different authors, their ecotoxicological impacts have not been examined in detail so far. Considering the above-mentioned gap in the scientific literature, the present work aimed to examine the toxicity of a home-made Ze-Fe LDHs nanocatalyst by employing aquatic organisms from different trophic levels. For this purpose, firstly, Zn-Fe LDHs catalyst was synthesized with a facile and cost-effective co-precipitation method and characterized by SEM, XRD, FT-IR, and nitrogen adsorption-desorption analyses. In the second part of the study, possible environmental risks of the Zn-Fe LDHs catalyst were tested using the marine photobacterium V. fischeri, the freshwater microalga P. subcapitata, the freshwater crustacean D. magna and the duckweed S. polyrhiza forming a battery assay. 
To the best of our knowledge, this is the first attempt to evaluate the multi-trophic acute toxicity of the $\mathrm{Zn}$-Fe LDHs catalyst.

\section{Results and Discussion}

\subsection{Zn-Fe LDHs Characterization}

The XRD pattern of the synthesized Zn-Fe LDHs is represented in Figure 1a. The peaks centered at $2 \theta$ of $12.1^{\circ}, 23.3^{\circ}, 34.5^{\circ}, 39.0^{\circ}, 45.9^{\circ}, 59.7^{\circ}$, and $61.2^{\circ}$ can be attributed to the $003,006,009,015,018,110,113$, and 113 crystalline planes of the synthesized sample, indicating the successful synthesis of LDHs [15]. In addition, the average crystallite size of the synthesized LDHs was determined as approximately $15 \mathrm{~nm}$ using Debye-Sherer's equation [41].
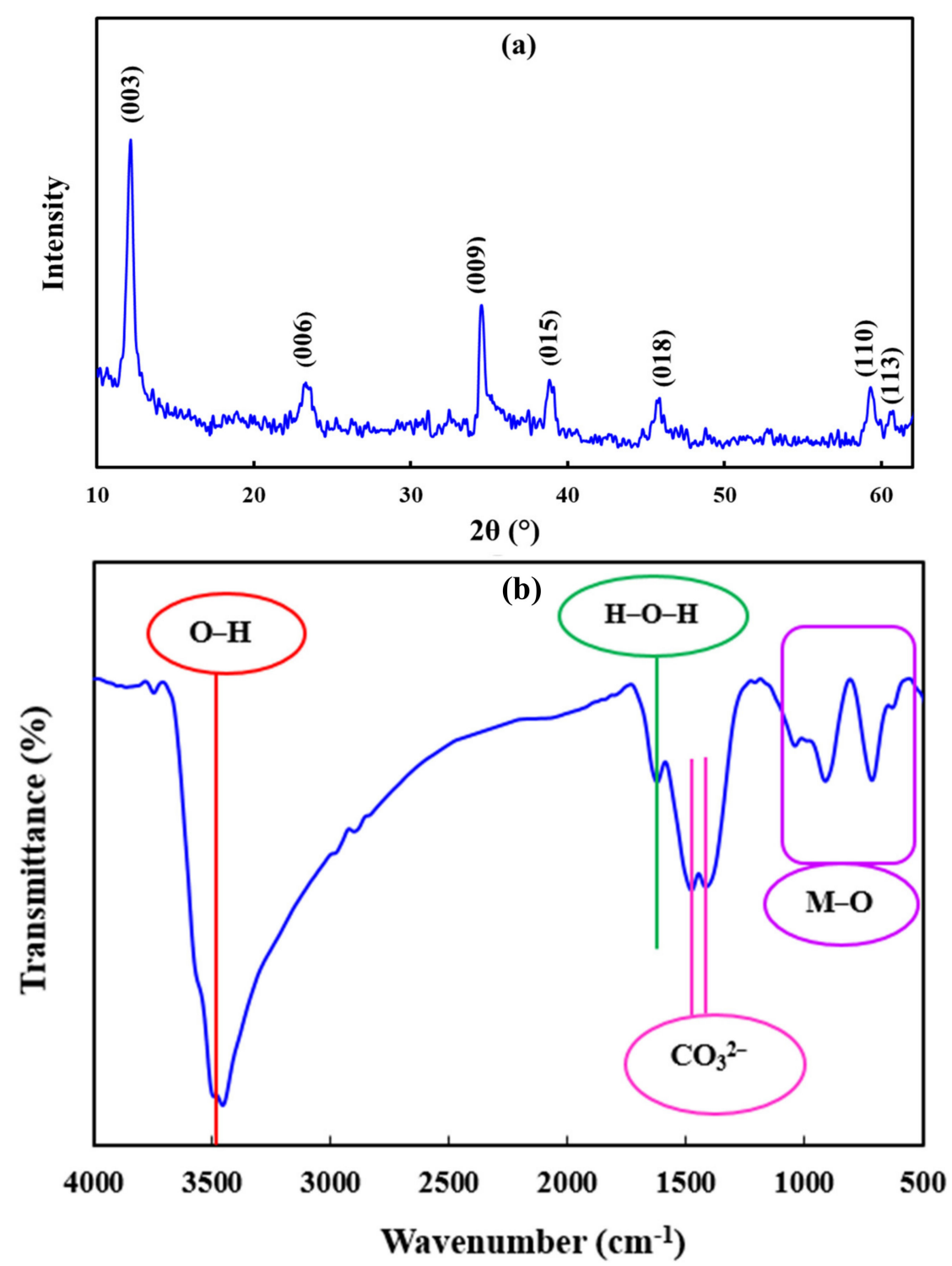

Figure 1. XRD pattern of nanolayered Zn-Fe LDHs (a); FT-IR spectrum of nanolayered Zn-Fe LDHs (b).

The FT-IR spectrum of the synthesized Zn-Fe LDHs was recorded in the wavenumber range of $500-4000 \mathrm{~cm}^{-1}$ to investigate the functional groups (See Figure $1 \mathrm{~b}$ ). The absorption peaks detected in the wavenumber lower than $1000 \mathrm{~cm}^{-1}$ can be ascribed to the vibration of the O-M-O and M-O groups ( $\mathrm{M}: \mathrm{Zn}^{2+}$ and $\mathrm{Fe}^{3+}$ cations) [42]. The absorption peaks centered at $1419 \mathrm{~cm}^{-1}$ and $1475 \mathrm{~cm}^{-1}$ are assigned to the carbonate $\left(\mathrm{CO}_{3}{ }^{2-}\right)$ anions placed in the 
interlayer region of LDHs [43]. The source of the carbonate anions in the interlayer region of LDHs can be attributed to the dissolution of $\mathrm{CO}_{2}$ molecules in distilled water used for synthesis [15]. The peak centered at about $1600 \mathrm{~cm}^{-1}$ is due to the bending vibration of water molecules that exist in the interlayer region of LDHs [44]. The strong and broad band observed in the wavenumber of $3500 \mathrm{~cm}^{-1}$ can be assigned to the $\mathrm{O}-\mathrm{H}$ groups attached to the layer surface of the LDHs and the O-H groups of the interlayered water molecules [45]. The SEM images of the synthesized Zn-Fe LDHs are represented in Figure 2. Layered morphology with an average thickness of $45 \pm 0.6 \mathrm{~nm}$ can be seen in the SEM images.
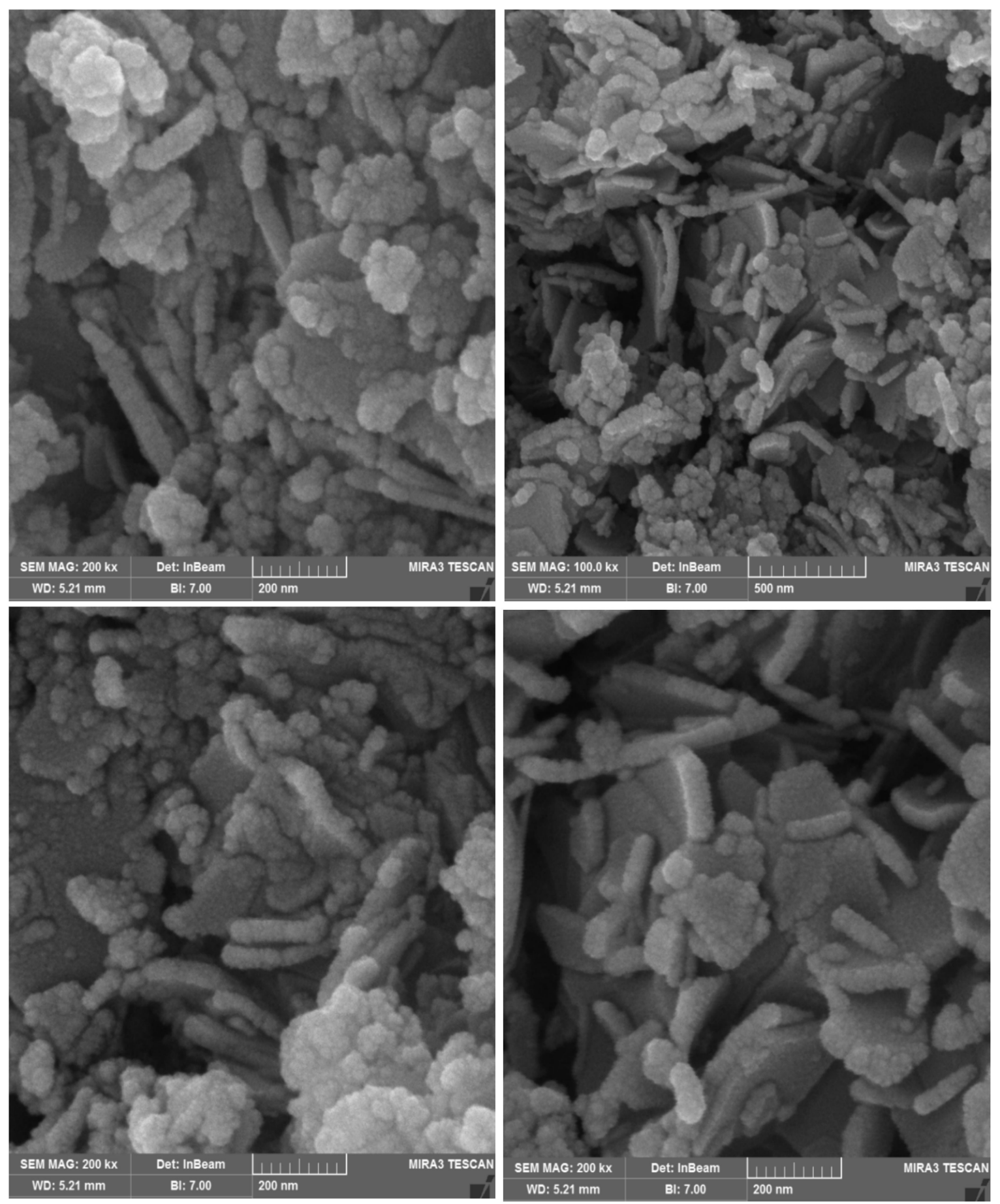

Figure 2. SEM images of the Zn-Fe LDHs. 
The nitrogen adsorption-desorption isotherm of the prepared $\mathrm{Zn}$-Fe LDHs is shown in Figure 3. According to the IUPAC classification, the synthesized LDHs represented type IV isotherm, confirming the mesoporous structure of the synthesized sample. Based on the Brunauer-Emmett-Teller (BET) analysis, the specific surface area of the synthesized LDHs was determined $46.9 \mathrm{~m}^{2} / \mathrm{g}$.

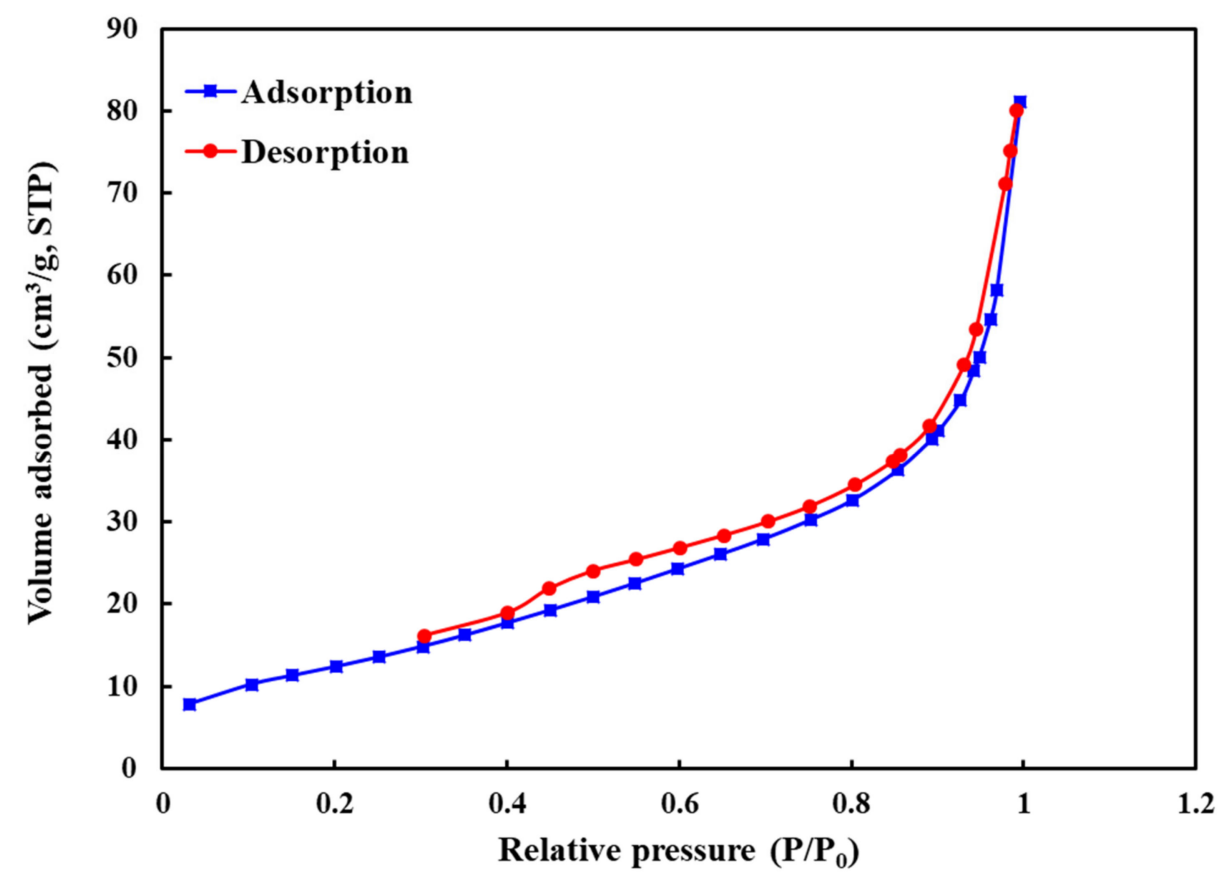

Figure 3. Nitrogen adsorption-desorption isotherm of Zn-Fe LDHs.

\subsection{Acute Toxicity Assessment}

The toxicity of NMs stems from the promotion of ROS production inducing cellular oxidative stress, or from direct interactions between these materials, their dissolution products (released metal ions), and proteins. Oxidative stress may cause the damage of lipids, membrane, carbohydrates, and deoxyribonucleic acid (DNA) via formation of disulfide, oxidation of methionine, and carbonylation of amino acid residues promoting the accumulation of nanoparticles $[29,46]$. The surface coating can cause inhibition of photosynthesis in algal tests; besides, nutrient uptake or movement and is also considered to be one of the possible toxicity routes of NMs [46,47]. The aquatic toxicity of the Zn-Fe LDHs towards test organisms being selected from different trophic levels is presented and discussed in the following sections.

\subsubsection{V. fischeri}

As aforementioned, the $V$. fischeri luminescence inhibition assay is one of the most frequently used ecotoxicological tests for the in vitro toxicity evaluation of different contaminants [48]. The bioluminescence of the Gram-negative marine bacterium $V$. fischeri is a result of biochemical reactions where a reduced flavin mononucleotide, a long-chain fatty acid aldehyde, and luciferase are involved. This process uses nicotinamide adenine dinucleotide hydrogen (NADH) as a cofactor for the reactions and is related to the central metabolism of the bacterium. Consequently, the inhibition of $\mathrm{V}$. fischeri bioluminescence strongly correlates with the toxicity of the test sample $[49,50]$.

Figure 4 displays the toxicity of Zn-Fe LDHs towards $V$. fischeri. Three catalyst preparation times, namely $\mathrm{t}=24,3$, and $1 \mathrm{~h}$ were evaluated with $V$. fischeri to question whether the toxic response depends on the sample preparation time. The appearance of all $\mathrm{Zn}-\mathrm{Fe}$ LDHs samples changed after stirring for $24 \mathrm{~h}$ and a thick white film formed on their surface. Moreover, all samples (Zn-Fe LDHs concentrations $=0.10-2.00 \mathrm{~g} / \mathrm{L}$ ) showed an increase in 
$\mathrm{pH}$ to $\approx 8.4$ and resistance to $\mathrm{pH}$ adjustment making $\mathrm{pH}$ re-adjustment to the working $\mathrm{pH}$ (7.0 \pm 0.2$)$ rather difficult. As a result, only the catalyst concentration of $0.10 \mathrm{~g} / \mathrm{L}$ could be tested for $24 \mathrm{~h}$-prepared $\mathrm{Zn}$-Fe LDHs samples. Under these test conditions, $24.4 \pm 1.2 \%$ and $68.5 \pm 0.8 \%$ relative inhibitions were observed with respect to the toxicant-free control for an exposure time of $t=15$ and $30 \mathrm{~min}$, respectively.
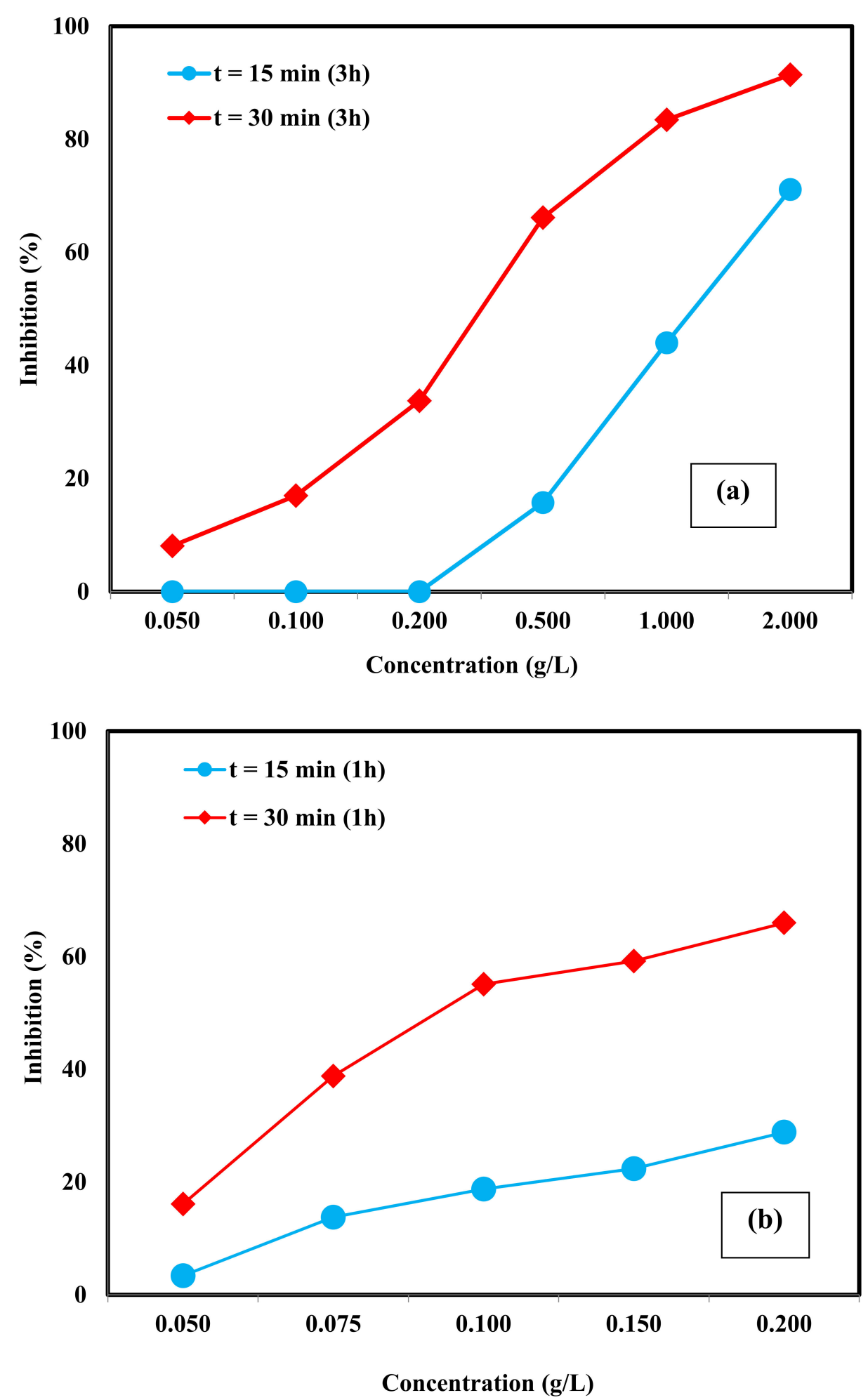

Figure 4. Mean relative inhibition ( $\pm \mathrm{SD} ; n=3$ ) towards $V$. fischeri after 15 and $30 \mathrm{~min}$ of exposure to $\mathrm{Zn}-\mathrm{Fe}$ LDHs toxicity test samples prepared within $3 \mathrm{~h}(\mathbf{a})$, and $1 \mathrm{~h}(\mathbf{b})$. 
As has been reported previously, NMs can be agglomerated into microscopic particles in a high ionic strength medium as in the present case, inducing a change in their morphology and instability in surface properties [51]. Therefore, modification of the NMs' structural properties after dispersion into the test media should be considered when evaluating toxicity. Based on the results obtained for 24 h-prepared toxicity samples, the experimental procedure was modified and the sample preparation time was reduced to $\mathrm{t}=3$ and $1 \mathrm{~h}$. As can be seen from Figure $4 \mathrm{a}$, after 15 min of exposure, only the concentrated samples $(=0.50,1.00$, and $2.00 \mathrm{~g} / \mathrm{L})$ showed an inhibitory effect on luminescence intensity. The lowest observed effect (a relative inhibition of $15.8 \pm 1.7 \%$ ) was found for $0.50 \mathrm{~g} / \mathrm{L}$ catalyst. On the other hand, for the exposure time of $30 \mathrm{~min}$, appreciable inhibition was observed for all tested concentrations. The $\mathrm{EC}_{50}$ values for the $3 \mathrm{~h}$-prepared $\mathrm{Zn}$-Fe LDHs samples were calculated as $1.20 \pm 0.12 \mathrm{~g} / \mathrm{L}$ and $0.32 \pm 0.03 \mathrm{~g} / \mathrm{L}$ for incubation times of 15 and $30 \mathrm{~min}$, respectively. As can be seen in Figure $4 \mathrm{~b}$, the highest luminescence inhibition was observed for the $\mathrm{Zn}$-Fe LDHs sample being prepared in $1 \mathrm{~h}$ at the concentration range of $0.05-0.20 \mathrm{~g} / \mathrm{L}$. The percent relative inhibition of $0.20 \mathrm{~g} / \mathrm{L}$ catalyst was found as $28.9 \pm 0.1 \%$ (instead of $0 \%$ for $3 \mathrm{~h}$-prepared sample) and $66.0 \pm 0.1 \%$ (instead of $33.8 \pm 0.6 \%$ for $3 \mathrm{~h}$ prepared sample) for an exposure time of 15 and $30 \mathrm{~min}$, respectively. The $\mathrm{EC}_{50}$ value was calculated as $0.31 \pm 0.03 \mathrm{~g} / \mathrm{L}$ for $\mathrm{t}=15 \mathrm{~min}$, whereas an $\mathrm{EC}_{50}$ value of $0.11 \pm 0.01 \mathrm{~g} / \mathrm{L}$ was obtained for $\mathrm{t}=30 \mathrm{~min}$. Sample preparation time affected the toxicity response due to effects such as metal ion release and changes in catalyst structure after the contact with the test medium.

In previous work, it was demonstrated that nano- $\mathrm{ZnO}$ toxicity $\left(\mathrm{EC}_{50}=1.17 \mathrm{mg} / \mathrm{L}\right)$ was possibly caused by $\mathrm{Zn}^{2+}$ release [52]. $\mathrm{Fe}^{3+}$ also proved to be very toxic towards $V$. fischeri $\left(\mathrm{EC}_{50}=0.44 \mathrm{mg} / \mathrm{L}\right)$ [53]. A similar trend was also observed for another gram-negative bacteria, recombinant luminescent $E$. coli, where $30-\mathrm{min} \mathrm{EC}_{50}$ values were found as $8.5 \mathrm{mg}$ $\mathrm{Fe}^{2+} / \mathrm{L}$ and $1.3 \mathrm{mg} \mathrm{Fe}{ }^{3+} / \mathrm{L}$ [54] speaking for a toxicity effect caused by metal ions and possible metal ion leaching from $\mathrm{Zn}-\mathrm{Fe}$ LDHs catalyst into the test medium.

\subsubsection{P. subcapitata}

Several interactions between microalgae and NMs can induce toxic response including shading/reduction of captured light, metal ions being released from NMs, oxidative stress, adsorption, absorption, and disruption of microalgae barriers [55]. The algal bioassay principle is based on growth rate inhibition being caused by different contaminants.

In the present study, Zn-Fe LDHs catalyst was found to be toxic towards P. subcapitata even at the lowest test concentration of $0.10 \mathrm{~g} / \mathrm{L}$. These experimental results are in agreement with previously published data for Zn-containing nanocatalysts. Aruoja et al. (2009) reported that bulk and nano- $\mathrm{ZnO}$ were quite toxic towards $P$. subcapitata with $\mathrm{EC}_{50}$ values of 0.037 and $0.047 \mathrm{mg} / \mathrm{L}$ for the bulk and nano- $\mathrm{ZnO}$, respectively [56]. Another study conducted by Franklin et al. (2007), where the effect of $\mathrm{ZnCl}_{2}$ on P. subcapitata was examined, reported an $\mathrm{EC}_{50}$ value of $0.060 \mathrm{mg} / \mathrm{L}$ [57]. Exposure of Scenedesmus quadricauda, typical freshwater green algae, to $\mathrm{Cu}-\mathrm{Mg}-\mathrm{Fe} \mathrm{LDH}$ resulted in serious growth inhibition at an incubation time of $72 \mathrm{~h}\left(\mathrm{EC}_{50}=10 \mathrm{mg} / \mathrm{L}\right)$ in another work [58]. It should be mentioned here that aggregation and morphological changes of the Zn-Fe LDHs catalyst were observed during the bioassay which could explain the toxic response. Thus, to gain further insight into the toxicity pathway and potential impacts of Zn-Fe LDH catalyst on microalgae, characterization of the LDHs before and after exposure to the test medium could be important.

\subsubsection{D. magna}

Among the invertebrates, D. magna as a representative of zooplankton and a key group for the food web structure has often been used in toxicity tests [47]. In addition to ROS-mediated toxic effects of NMs, "biological surface coating" (i.e., the attachment or adsorption of NMs on the outer surface of the organisms) is suggested as a potential toxicity trigger for test organisms like D. magna [46]. Figure 5 depicts the effect of Zn-Fe 
LDHs catalyst concentration (0.05-0.20 g/L) on D. magna response for $\mathrm{t}=24$ and $48 \mathrm{~h}$. As obvious from Figure 5, $10 \pm 2 \%$ and $65 \pm 20 \%$ mortalities were observed for 0.05 and $0.20 \mathrm{~g} / \mathrm{L}$ catalyst $\mathrm{t}=24 \mathrm{~h}$, respectively. Mortalities were higher compared to the test control for all tested concentrations at $\mathrm{t}=48 \mathrm{~h}$; e.g., $35 \pm 20 \%$ for $0.05 \mathrm{~g} / \mathrm{L}$ and $75 \pm 10 \%$ for $0.20 \mathrm{~g} / \mathrm{L}$. Similar to $V$. fischeri, D. magna toxicity of Zn-Fe LDHs also depended on the exposure time; toxicity of the $\mathrm{Zn}-\mathrm{Fe} \mathrm{LDHs}$ catalyst increased with prolonged test durations. It was observed that Zn-Fe LDHs catalyst particles adhered to the antennae of the daphnids when higher catalyst concentrations and longer incubation times were applied. Despite external surface adhesion, no catalyst was seen in the gut tract of the test organisms. The $\mathrm{EC}_{50}$ concentrations of $\mathrm{Zn}-\mathrm{Fe} \mathrm{LDH}$ to $D$. magna were calculated as $0.17 \pm 0.02$ and $0.10 \pm 0.01 \mathrm{~g} / \mathrm{L}$ for 24 and $48 \mathrm{~h}$ of exposure, respectively.

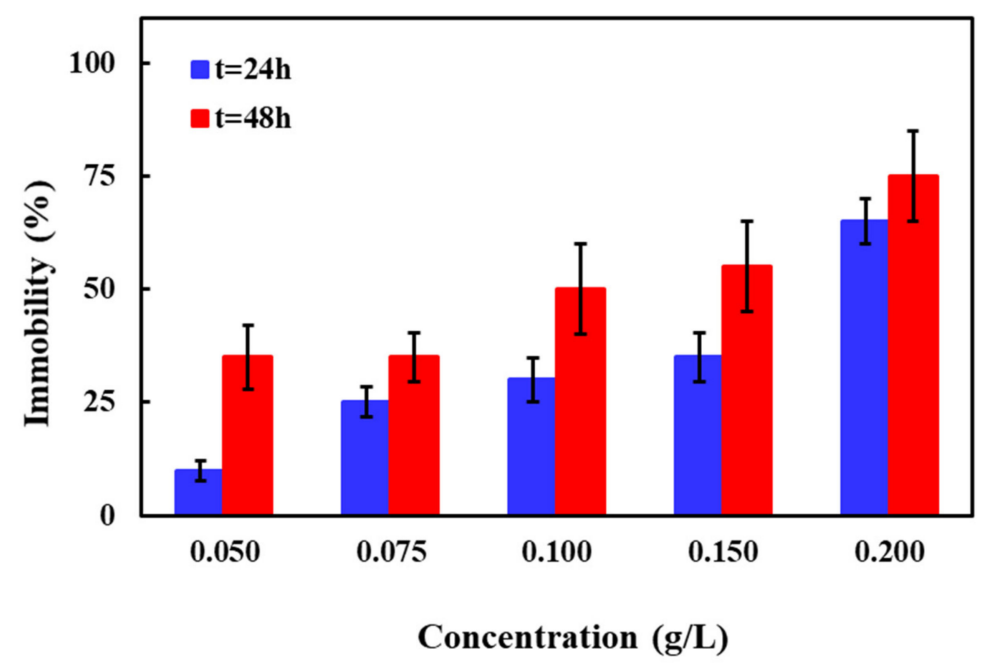

Figure 5. Mean death/immobilization ( $(\mathrm{SD} ; n=5)$ of $D$. magna after 24 and $48 \mathrm{~h}$ of exposure to concentrations of $0.05,0.075,0.10,0.15$, and $0.20 \mathrm{~g} / \mathrm{L} \mathrm{Zn-Fe} \mathrm{LDHs} \mathrm{catalyst.}$

Studies devoted to the toxicity of $\mathrm{ZnO}-\mathrm{NMs}$ towards invertebrates and vertebrates reported that zinc ions released from $\mathrm{ZnO}-\mathrm{NMs}$ rather than the particle size are the main factor of toxicity. In the study of Bacchetta et al. (2016), the $48 \mathrm{~h} \mathrm{LC} 50$ was $1.02 \mathrm{mg} / \mathrm{L}$ and $1.10 \mathrm{mg} / \mathrm{L}$ for $30 \mathrm{~nm}$ and $80-100 \mathrm{~nm} \mathrm{ZnO}$ catalyst, respectively [59]. Blinova et al. (2010) reported that the toxicity of $\mathrm{CuO}$ NMs in river water is related to the release of dissolved metal ions [60]. On the other hand, the acute toxicity of $\mathrm{TiO}_{2}$ and $\mathrm{Fe}_{3} \mathrm{O}_{4}$ in daphnids, for instance, was attributed to a physical inhibition of molting, ultimately inducing death $[46,47,61]$.

\subsubsection{S. polyrhiza}

As mentioned above, the duckweed test is one of the most recognized and routine higher plant toxicity tests for assessing the impacts of contaminants on the aquatic environment. Species from monocotyledonous free-floating aquatic macrophytes of the Lemnaceae family are frequently being used in ecotoxicology studies. The simple anatomy and ease with which they can be handled make them ideal test organisms. However, due to the variety of exposure routes, these higher plants demonstrate a range of sensitivities to the toxic pollutants [40]. In this work, a $72 \mathrm{~h}$-growth inhibition test [62] was conducted for the Zn-Fe LDHs catalyst to elucidate its inhibitory effect towards S. polyrhiza at a concentration range of 0.075 to $2.00 \mathrm{~g} / \mathrm{L}$ (See Table S1 and Figure 6). As evident from Figure 6, a fair inhibition ( $32 \pm 6 \%$ ) was evidenced for the lowest studied Zn-Fe LDHs concentration $(0.075 \mathrm{~g} / \mathrm{L}$ ). Increasing the catalyst concentration to 0.50 and $2.00 \mathrm{~g} / \mathrm{L}$ led to a gradual increase in S. polyrhiza growth inhibition from $32 \pm 6 \%$ to $41 \pm 14 \%$ and $66 \pm 12 \%$, respectively. Based on these results, $\mathrm{EC}_{50}$ values were calculated at $0.81 \pm 0.19 \mathrm{~g} / \mathrm{L}$ for an exposure time of $72 \mathrm{~h}$. At the end of the test duration, a pale-yellow color of the fronds was visually observed 
for all investigated Zn-Fe LDHs catalyst concentrations (Figure S1), which was considered to be indicative of metal dissolution from the catalyst causing a morphological change of the catalyst. Moreover, the formation of the additional fronds (more than two) was not observed at the highest tested catalyst concentration of $2.00 \mathrm{~g} / \mathrm{L}$ (Figure S1g).

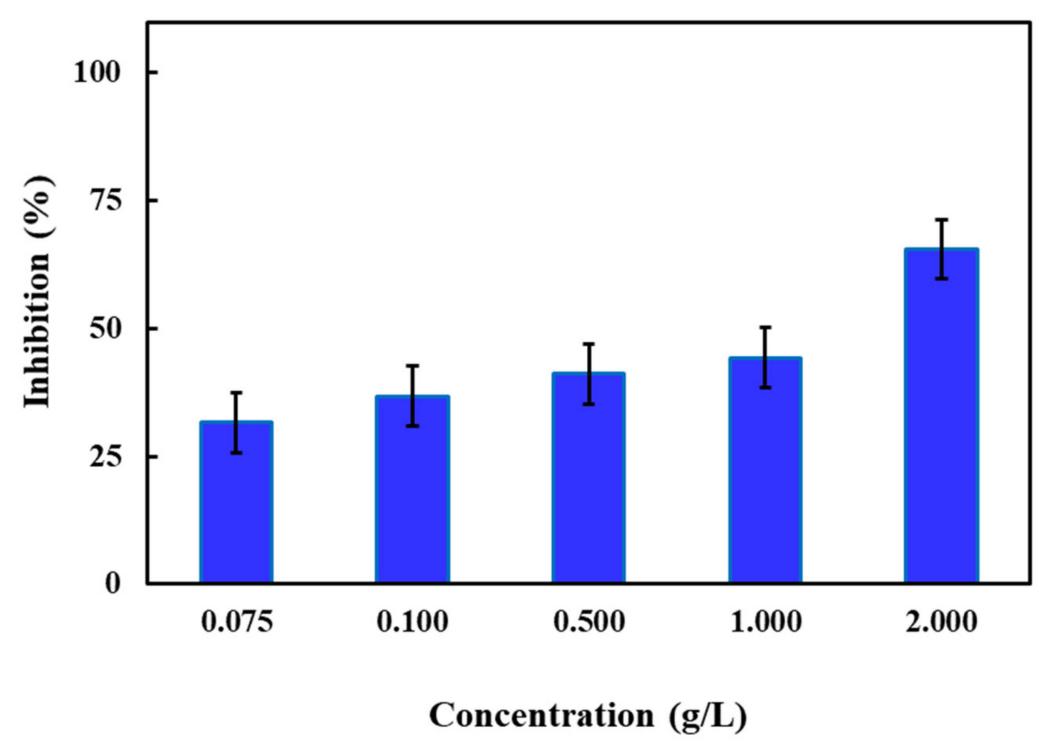

Figure 6. Mean growth inhibition ( $\pm \mathrm{SD} ; n=7$ ) of $S$. polyrhiza after $72 \mathrm{~h}$ of exposure to concentrations of $0.075,0.10,0.50,1.00$, and $2.00 \mathrm{~g} / \mathrm{L} \mathrm{Zn-Fe} \mathrm{LDHs} \mathrm{catalyst.}$

All acute toxicity test results obtained with different test organisms were summarized in Table S1. From Table S1 it is evident that the catalyst sample is highly toxic (inhibitory) towards the selected test organisms in its typical working (application range) range and the toxic response increases with extended incubation time which would be an important remark to applicants of nanomaterials.

\section{Materials and Methods}

\subsection{Synthesis and Characterization}

Iron (III) chloride hexahydrate $\left(\mathrm{FeCl}_{3} \cdot 6 \mathrm{H}_{2} \mathrm{O}\right)$, sodium hydroxide $(\mathrm{NaOH})$, and zinc chloride $\left(\mathrm{ZnCl}_{2}\right)$ were purchased from Merck Co., Gernsheim, Germany. The facile coprecipitation method was used to synthesize the $\mathrm{Zn}-\mathrm{Fe} \mathrm{LDHs}$. In the first step, $1.00 \mathrm{mmol}$ of $\mathrm{FeCl}_{3} \cdot 6 \mathrm{H}_{2} \mathrm{O}$ and $3.00 \mathrm{mmol}$ of $\mathrm{ZnCl}_{3}$ were dissolved in distilled water. Then, the $\mathrm{pH}$ of the solution was adjusted to $\mathrm{pH} 8$ by dropwise addition of $\mathrm{NaOH}$ solution under a nitrogen atmosphere and vigorous stirring. The resultant mixture was further stirred for $24 \mathrm{~h}$ under a nitrogen atmosphere at room temperature. Finally, the synthesized LDHs particles were collected and separated by centrifugation and dried at $50{ }^{\circ} \mathrm{C}$ for $5 \mathrm{~h}$ after washing with distilled water.

A Philips X-ray diffractometer with a model of PW1730 (Amsterdam, the Netherlands) was used to study the crystalline structure of the synthesized Zn-Fe LDHs. The morphology of the synthesized sample was investigated using a Tescan scanning electron microscope with a model of MIRA3 (Brno, Czech Republic). The thickness of the synthesized ZnFe LDHs was determined using SEM images and Digimizer software, and the average thickness was reported. A Bruker Fourier transform infrared (FT-IR) spectrometer with a model of Tensor (Hamburg, Germany) was used to determine the functional groups of the synthesized LDHs. The nitrogen adsorption-desorption isotherm of the synthesized $\mathrm{Zn}$-Fe LDHs was determined using the BELSORP device with a model of Mini II (BEL, Osaka, Japan). 


\subsection{Acute Toxicity Assessment}

\subsubsection{Preparation of Toxicity Samples}

The samples for the toxicity tests were prepared by the addition of an appropriate amount of the $\mathrm{Zn}-\mathrm{Fe} \mathrm{LDH}$ into the culturing medium for each test organism. The wide concentration ranges of $\mathrm{Zn}-\mathrm{Fe} \mathrm{LDH}$ used in this work were chosen based on related applications reported in the scientific literature [10,12-15]. Appropriate volumes specified for the toxicity tests were prepared by adding the $\mathrm{Zn}-\mathrm{Fe} \mathrm{LDH}$ catalyst into the test medium through an automatic pipette forming catalyst + test medium suspensions. All test samples were continuously stirred with a magnetic stirrer before and during their transfer into the test vials to ensure that the same concentration of catalyst particles was taken for each replicate. The suspensions remained stable during the tests and no ultrasonication was needed for sample mixing and preparation. Toxicity tests were conducted using commercially available test kits. Algaltoxkit F, Daphtoxkit F, and Duckweed Toxkit F were purchased from MicroBioTests Inc. company (Gent, Belgium and Masku, Finland), whereas the test kits of the marine photobacteria were obtained from Aboatox-company (BioTox ${ }^{\mathrm{TM}}$, Aboatox Oy, Masku, Finland). Table S1 gives information about all toxicity test procedures used in this study.

All data were presented as means \pm standard deviations. The standard deviation for each toxicity test is reported in the form of error bars in the figures. Duplicates, triplicates, pentaplicates, and eight replicates were used to carry out the bioassays with V. fischeri, P. subcapitata, D. magna, and S. polyrhiza, respectively, depending on the test procedure. Statistical significance and quality criteria were tested using the software provided by Aboatox (Gent, Belgium and Masku, Finland) and MicroBioTests Inc. companies. The $\mathrm{EC}_{50}$ (= median effective concentration) defined herein as the effective $\mathrm{Zn}-\mathrm{Fe} \mathrm{LDHs}$ catalyst concentration causing 50\% reduction in the bioluminescence, growth and/or death/immobilization were calculated using specific guidelines for each test organisms. The significance level in all calculations was set at $p<0.05$.

\subsubsection{V. fischeri}

The acute toxicity as percent relative bioluminescence inhibition towards the photobacterium $V$. fischeri was measured with a commercial bioassay kit according to the ISO $11348-3$ test protocol [63]. Briefly, catalysts were dissolved in $2 \% w / v \mathrm{NaCl}$ solution and all the samples' $\mathrm{pH}$ values were adjusted to a fixed value of $7.0 \pm 0.2$. The lyophilized bacteria with reconstituted reagents were equilibrated at $+4{ }^{\circ} \mathrm{C}$ for at least $30 \mathrm{~min}$ and then stabilized at $+15^{\circ} \mathrm{C}$ for at least $30 \mathrm{~min}$ before pipetting the bacteria suspension into the samples. For each dilution level two parallel samples were prepared and the luminescence intensity was recorded in all test tubes, including controls, after $15 \mathrm{~min}$ and $30 \mathrm{~min}$. The test procedure was as follows; firstly, all samples (concentration range $=0.10-2.00 \mathrm{~g} / \mathrm{L}$ ) were prepared according to the assay procedure and left for stirring overnight for $24 \mathrm{~h}$. However, since the catalyst was in particle form and might aggregate after a while, the sample preparation time was reduced from 24 to 3 and $1 \mathrm{~h}$ and a lower catalyst concentration range of $0.05-0.20 \mathrm{~g} / \mathrm{L}$ was selected. In order to be sure that no positive intensity inhibition was observed due to precipitation/aggregation of the catalyst particles, all samples were mixed with the pipette tip just before each luminescence measurement.

\subsubsection{P. subcapitata}

The algal growth inhibition bioassay was performed using freshwater microalgae stock culture $P$. subcapitata from the test kit. The toxicity test was based on percent relative growth inhibition towards P. subcapitata and performed according to the ISO 8692 test protocol [64]. Test conditions were set as $\mathrm{T}=24 \pm 1{ }^{\circ} \mathrm{C}$ and $\mathrm{pH}=8.1 \pm 0.2$, and test organisms were exposed to continuous side illumination with cool white light (5000-6000 lux). Experiments were performed in triplicates in $25 \mathrm{~mL}$ incubation vials with an initial algal cell count of around 10,000 cells $/ \mathrm{mL}$. Algal biomass (optical density) measurements were carried out at $\mathrm{t}=24,48$ and $72 \mathrm{~h}$ for catalyst concentrations in the range of $0.10-2.00 \mathrm{~g} / \mathrm{L}$. 


\subsubsection{D. magna}

The dormant eggs (ephippia) of the freshwater crustacean D. magna were used in the toxicity bioassay. Acute toxicity tests were based on percent death and/or immobilization rates being observed for $D$. magna after an incubation time of $\mathrm{t}=24$ and $48 \mathrm{~h}$ according to the Standard Operational Procedure of Daphtoxkit F based on the OECD 202 guideline [37,65]. According to the standard test protocol, before each test, ephippias were hatched within $72 \mathrm{~h}$ and thereafter the neonates (newborn daphnia) were fed with the unicellular alga Spirulina sp. (also provided with the test kit) for $2 \mathrm{~h}$. Briefly, five daphnid neonates per test cell were incubated in the dark at $\mathrm{T}=20 \pm 2{ }^{\circ} \mathrm{C}$ for up to $\mathrm{t}=48 \mathrm{~h}$ in four replicates. Daphnids were exposed to a catalyst concentration range of $0.05-2.00 \mathrm{~g} / \mathrm{L}$. The quality criteria of the tests were completely fulfilled as in the test control immobilization of daphnids did not exceed $10 \%$. The number of immobilized daphnids (the toxicity endpoint) was determined at $\mathrm{t}=24$ and $48 \mathrm{~h}$.

\subsubsection{S. polyrhiza}

The S. polyrhiza toxicity bioassay test is based on measuring the decrease (or absence) of growth of the germinated "turions" (dormant vegetative stages, vegetative buds), after $72 \mathrm{~h}$ of exposure in comparison to the test control. The experimental procedure was based on ISO 20227 test protocol [62]. Briefly, the vegetative buds were firstly incubated for three days at $25^{\circ} \mathrm{C}$ in a petri dish under continuous illumination with 6000 lux to obtain germinated turions. The $\mathrm{pH}$ of the growth medium was adjusted to $5.5 \pm 0.2$. The germinated turions were transferred into each of the 48 cups of the multi-well test plate containing controls and different concentrations of the catalysts. "Digital pictures" of the test plates were taken to measure the size (area) of the small "first frond" of the duckweeds in the test cups at the beginning and after $\mathrm{t}=72 \mathrm{~h}$ of exposure. The test areas were measured with the "Image J" software [66]. Eight replicates were used for toxicity evaluation. Validity criteria of the tests were completely fulfilled as the mean growth of the first fronds in the cups of the control row after $\mathrm{t}=72 \mathrm{~h}$ incubation at $25^{\circ} \mathrm{C}$ and under 6000 lux illumination were at least $10 \mathrm{~mm}^{2}$. If more than one frond was developed in the same cup, only the largest of these was considered.

\section{Conclusions}

In the present study, Zn-Fe nanolayered double hydroxide (Zn-Fe LDHs) was synthesized, characterized, and comparatively examined for its toxic impacts with four different bioassays using test organisms from the different trophic levels. Firstly, the Zn-Fe LDHs catalyst was prepared using a co-precipitation method. The XRD pattern of the catalyst material confirmed the successful synthesis of Zn-Fe LDHs with an average crystallite size of $15 \mathrm{~nm}$. Layered morphology with an average thickness of $45 \mathrm{~nm}$ was observed in the SEM images. The synthesized $\mathrm{Zn}$-Fe LDHs revealed a type IV nitrogen adsorption-desorption isotherm, indicating the mesoporous structure. Besides, the specific surface area of the Zn-Fe LDHs was obtained as $46.9 \mathrm{~m}^{2} / \mathrm{g}$ using BET analysis. A comprehensive acute toxicity assessment was also undertaken for the home-made Zn-Fe LDHs catalyst. Results demonstrated a concentration and preparation time-dependent response for all tested organisms. P. subcapitata (complete inhibition at all tested catalyst concentrations) was found to be most sensitive to the Zn-Fe LDHs catalyst, whereas S. polyrhiza $\left(\mathrm{EC}_{50}=0.81 \pm 0.19 \mathrm{~g} / \mathrm{L}\right)$ appeared to be the least sensitive test organism. $V$. fischeri toxicity results highlighted the importance of "preparation time" of the Zn-Fe LDHs catalyst samples before toxicity analysis. The $\mathrm{EC}_{50}$ values calculated for the $1 \mathrm{~h}$-prepared catalyst test solutions $\left(\mathrm{EC}_{50,15 \mathrm{~min}}=0.31 \pm 0.03 \mathrm{~g} / \mathrm{L}\right.$ and $\left.\mathrm{EC}_{50,30 \mathrm{~min}}=0.11 \pm 0.01 \mathrm{~g} / \mathrm{L}\right)$ were lower than that of the $3 \mathrm{~h}$-prepared solutions $\left(\mathrm{EC}_{50,15 \mathrm{~min}}=1.20 \pm 0.12 \mathrm{~g} / \mathrm{L}\right.$ and $\mathrm{EC}_{50,30} \mathrm{~min}=0.32 \pm 0.03 \mathrm{~g} / \mathrm{L}$ ). $\mathrm{EC}_{50}$ values for $D$. magna were detected as $0.17 \pm 0.02 \mathrm{~g} / \mathrm{L}$ and $0.10 \pm 0.01 \mathrm{~g} / \mathrm{L}$ for an incubation time of 24 and $48 \mathrm{~h}$, respectively. The present study highlighted the importance of combining biotests with chemical analysis to provide a more complete picture of the ecotoxicological effects of engineered nanomaterials as well as structure-toxicity relationships. 
From the study, it could be concluded that several factors affected aquatic toxicity findings; the exposure time together with the type of test organism and physicochemical properties of the standard bioassay test medium all have to be considered when assessing the toxicity of engineered nanomaterials since these might affect the dispersibility, aggregation, sedimentation, and the dissolution of the tested catalyst samples.

Supplementary Materials: The following are available online, Figure S1: Changes in the fronds of S. polyrhiza exposed to the different concentrations of $\mathrm{Zn}-\mathrm{Fe} \mathrm{LDH}$. The figure shows fronds for test control (a), 0.05 g/L (b), 0.075 g/L (c), 0.10 g/L (d), 0.50 g/L (e), 1.00 g/L (f), and 2.00 g/L (g) Zn-Fe LDH exposure, Table S1: Summary of toxicity test procedures used in this study.

Author Contributions: Reviewing and editing, experiments, characterization of samples, O.K.-U.; reviewing and editing, T.Ö.H.; supervision, reviewing and editing, I.A.-A.; experiments, characterization of samples, reviewing and editing, S.A.-O.; supervision, reviewing and editing, A.K.; reviewing and editing, M.K.; resources, characterization of samples, Y.O. All authors have read and agreed to the published version of the manuscript.

Funding: This research was funded by Istanbul Technical University under project Nr. MAB-201942237. Also, this research is supported by a research grant (Post Doc, S. Arefi-Oskoui) of the University of Tabriz (S2058-99.07.21). This research was funded by Nanjing Forestry University (Grant Nos. NFU163020203, NFU163020217 and NFU163020139) and the National Natural Science Foundation of China (5201101466).

Data Availability Statement: Data are contained within the article or supplementary material.

Acknowledgments: The authors are thankful for the financial support of Istanbul Technical University under project Nr. MAB-2019-42237. Also, this research is supported by a research grant (Post Doc, S. Arefi-Oskoui) of the University of Tabriz (S2058-99.07.21). Y. Orooji acknowledges the financial support provided by the Nanjing Forestry University (Grant Nos. NFU163020203, NFU163020217 and NFU163020139) and the National Natural Science Foundation of China (5201101466).

Conflicts of Interest: The authors declare no conflict of interest.

Sample Availability: Zn-Fe layered double hydroxides can be resynthesized and made available upon request.

\section{References}

1. Mishra, G.; Dash, B.; Pandey, S. Layered double hydroxides: A brief review from fundamentals to application as evolving biomaterials. Appl. Clay Sci. 2018, 153, 172-186. [CrossRef]

2. Tang, S.; Yao, Y.; Chen, T.; Kong, D.; Shen, W.; Lee, H.K. Recent advances in the application of layered double hydroxides in analytical chemistry: A review. Anal. Chim. Acta 2020, 1103, 32-48. [CrossRef]

3. Daneshvar, H.; Dorraji, M.S.; Amani-Ghadim, A.; Rasoulifard, M. Enhanced sonocatalytic performance of ZnTi nano-layered double hydroxide by substitution of $\mathrm{Cu}$ (II) cations. Ultrason. Sonochem. 2019, 58, 104632. [CrossRef] [PubMed]

4. Khodam, F.; Amani-Ghadim, H.R.; Aber, S.; Amani-Ghadim, A.R.; Ahadzadeh, I. Neodymium doped mixed metal oxide derived from CoAl-layered double hydroxide: Considerable enhancement in visible light photocatalytic activity. J. Ind. Eng. Chem. 2018, 68, 311-324. [CrossRef]

5. Boudaoud, N.; Miloudi, H.; Bouazza, D.; Adjdir, M.; Tayeb, A.; Fortuny, A.; Demey, H.; Sastre, A.M. Removal of Zinc from Aqueous Solutions Using Lamellar Double Hydroxide Materials Impregnated with Cyanex 272: Characterization and Sorption Studies. Molecules 2020, 25, 1263. [CrossRef]

6. Arrabito, G.; Bonasera, A.; Prestopino, G.; Orsini, A.; Mattoccia, A.; Martinelli, E.; Pignataro, B.; Medaglia, P.G. Layered double hydroxides: A toolbox for chemistry and biology. Crystals 2019, 9, 361. [CrossRef]

7. Yang, G.; Takei, T.; Yanagida, S.; Kumada, N. Enhanced supercapacitor performance based on CoAl layered double hydroxidepolyaniline hybrid electrodes manufactured using hydrothermal-electrodeposition technology. Molecules 2019, 24, 976. [CrossRef]

8. Cai, Z.; Bu, X.; Wang, P.; Ho, J.C.; Yang, J.; Wang, X. Recent advances in layered double hydroxide electrocatalysts for the oxygen evolution reaction. J. Mater. Chem. 2019, 7, 5069-5089. [CrossRef]

9. Shao, M.; Zhang, R.; Li, Z.; Wei, M.; Evans, D.G.; Duan, X. Layered double hydroxides toward electrochemical energy storage and conversion: Design, synthesis and applications. Chem. Commun. 2015, 51, 15880-15893. [CrossRef]

10. Motlagh, P.Y.; Khataee, A.; Rad, T.S.; Hassani, A.; Joo, S.W. Fabrication of ZnFe-layered double hydroxides with graphene oxide for efficient visible light photocatalytic performance. J. Taizwan Inst. Chem. Eng. 2019, 101, 186-203. [CrossRef]

11. Mohapatra, L.; Parida, K. A review on the recent progress, challenges and perspective of layered double hydroxides as promising photocatalysts. J. Mater. Chem. 2016, 4, 10744-10766. [CrossRef] 
12. Figueiredo, M.P.; Cunha, V.R.; Leroux, F.; Taviot-Gueho, C.; Nakamae, M.N.; Kang, Y.R.; Souza, R.B.; Martins, A.M.C.; Koh, I.H.J.; Constantino, V.R. Iron-based layered double hydroxide implants: Potential drug delivery carriers with tissue biointegration promotion and blood microcirculation preservation. ACS Omega 2018, 3, 18263-18274. [CrossRef]

13. Younes, H.A.; Khaled, R.; Mahmoud, H.M.; Nassar, H.F.; Abdelrahman, M.M.; El-Ela, F.I.A.; Taha, M. Computational and experimental studies on the efficient removal of diclofenac from water using ZnFe-layered double hydroxide as an environmentally benign absorbent. J. Taiwan Inst. Chem. Eng. 2019, 102, 297-311. [CrossRef]

14. Chaillot, D.; Bennici, S.; Brendlé, J. Layered double hydroxides and LDH-derived materials in chosen environmental applications: A review. Environ. Sci. Pollut. Res. Int. 2020. [CrossRef] [PubMed]

15. Khataee, A.; Arefi-Oskoui, S.; Samaei, L. ZnFe-Cl nanolayered double hydroxide as a novel catalyst for sonocatalytic degradation of an organic dye. Ultrason. Sonochem. 2018, 40, 703-713. [CrossRef] [PubMed]

16. Gholami, P.; Khataee, A.; Soltani, R.D.C.; Dinpazhoh, L.; Bhatnagar, A. Photocatalytic degradation of gemifloxacin antibiotic using Zn-Co-LDH@ biochar nanocomposite. J. Hazard. Mater. 2020, 382, 121070. [CrossRef] [PubMed]

17. Rad, T.S.; Ansarian, Z.; Soltani, R.D.C.; Khataee, A.; Orooji, Y.; Vafaei, F. Sonophotocatalytic activities of FeCuMg and CrCuMg LDHs: Influencing factors, antibacterial effects, and intermediate determination. J. Hazard. Mater. 2020, 399, 123062. [CrossRef]

18. Gu, Z.; Atherton, J.J.; Xu, Z.P. Hierarchical layered double hydroxide nanocomposites: Structure, synthesis and applications. Chem. Commun. 2015, 51, 3024-3036. [CrossRef]

19. Mohamed, F.; Abukhadra, M.R.; Shaban, M. Removal of safranin dye from water using polypyrrole nanofiber/Zn-Fe layered double hydroxide nanocomposite (Ppy NF/Zn-Fe LDH) of enhanced adsorption and photocatalytic properties. Sci. Total Environ. 2018, 640, 352-363. [CrossRef]

20. Liang, C.; Feng, X.; Yu, J.; Jiang, X. Graphene oxide/Mg-Fe layered double hydroxide composites for highly efficient removal of heavy metal ions from aqueous solution. Desal. Wat. Treat. 2018, 132, 109-119. [CrossRef]

21. Di, G.; Zhu, Z.; Zhang, H.; Zhu, J.; Lu, H.; Zhang, W.; Qiu, Y.; Zhu, L.; Küppers, S. Simultaneous removal of several pharmaceuticals and arsenic on Zn-Fe mixed metal oxides: Combination of photocatalysis and adsorption. Chem. Eng. J. 2017, 328, 141-151. [CrossRef]

22. Lu, H.; Zhu, Z.; Zhang, H.; Zhu, J.; Qiu, Y.; Zhu, L.; Küppers, S. Fenton-like catalysis and oxidation/adsorption performances of acetaminophen and arsenic pollutants in water on a multimetal Cu-Zn-Fe-LDH. ACS Appl. Mater. Interfaces 2016, 8, $25343-25352$. [CrossRef] [PubMed]

23. Yan, J.; Chen, Y.; Qian, L.; Gao, W.; Ouyang, D.; Chen, M. Heterogeneously catalyzed persulfate with a CuMgFe layered double hydroxide for the degradation of ethylbenzene. J. Hazard. Mater. 2017, 338, 372-380. [CrossRef] [PubMed]

24. Zhao, X.; Niu, C.; Zhang, L.; Guo, H.; Wen, X.; Liang, C.; Zeng, G. Co-Mn layered double hydroxide as an effective heterogeneous catalyst for degradation of organic dyes by activation of peroxymonosulfate. Chemosphere 2018, 204, 11-21. [CrossRef]

25. Abderrazek, K.; Uheida, A.; Seffen, M.; Muhammed, M.; Srasra, N.F.; Srasra, E. Photocatalytic degradation of indigo carmine using [Zn-Al] LDH supported on PAN nanofibres. Clay Miner. 2015, 50, 185-197. [CrossRef]

26. Barik, S.; Behera, L.; Badamali, S.K. Assessment of thermal and antimicrobial properties of PAN/Zn-Al layered double hydroxide nanocomposites. Compos. Interfaces 2017, 24, 579-591. [CrossRef]

27. Wang, Z.; Yu, H.; Ma, K.; Chen, Y.; Zhang, X.; Wang, T.; Li, S.; Zhu, X.; Wang, X. Flower-like surface of three-metal-component layered double hydroxide composites for improved antibacterial activity of lysozyme. Bioconjugate Chem. 2018, 29, 2090-2099. [CrossRef]

28. Buchman, J.T.; Hudson-Smith, N.V.; Landy, K.M.; Haynes, C.L. Understanding nanoparticle toxicity mechanisms to inform redesign strategies to reduce environmental impact. Acc. Chem. Res. 2019, 52, 1632-1642. [CrossRef]

29. Callaghan, N.I.; MacCormack, T.J. Ecophysiological perspectives on engineered nanomaterial toxicity in fish and crustaceans. Comp. Biochem. Physiol. C: Pharmacol. Toxicol. Endocrinol. 2017, 193, 30-41. [CrossRef]

30. Rand, G.M. Fundamentals of Aquatic Toxicology: Effects, Environmental Fate and Risk Assessment; CRC Press: Boca Raton, FL, USA, 1995.

31. Danabas, D.; Ates, M.; Tastan, B.E.; Cimen, I.C.C.; Unal, I.; Aksu, O.; Kutlu, B. Effects of Zn and ZnO nanoparticles on artemia salina and daphnia magna Organisms: Toxicity, accumulation and elimination. Sci. Total Environ. 2020, 711, 134869. [CrossRef]

32. Olmez-Hanci, T.; Arslan-Alaton, I.; Dursun, D. Investigation of the toxicity of common oxidants used in advanced oxidation processes and their quenching agents. J. Hazard. Mater. 2014, 278, 330-335. [CrossRef]

33. Farré, M.; Barceló, D. Toxicity testing of wastewater and sewage sludge by biosensors, bioassays and chemical analysis. TrAC Trends Anal. Chem. 2003, 22, 299-310. [CrossRef]

34. Ghosh, P.; Thakur, I.S.; Kaushik, A. Bioassays for toxicological risk assessment of landfill leachate: A review. Ecotoxicol. Environ. Saf. 2017, 141, 259-270. [CrossRef] [PubMed]

35. International Organization for Standardization (ISO). Water Quality_Determination of the Inhibition of the Mobility of Daphnia Magna Straus (Cladocera, Crustacea); 6341; International Organisation for Standardization: Geneva, Switzerland, 2012.

36. Agency, U.E.P. Methods for Measuring the Acute Toxicity of Effluents and Receiving Waters to Freshwater and Marine Organisms, 5th ed.; (USEPA), U.S. Environmental Protection Agency Office of Water: Washington, DC, USA, 2001.

37. OECD. Guidelines for the Testing of Chemicals/Section 2: Effects on Biotic Systems, Test No. 202: Daphnia sp. Acute Immobilisation Test; OECD Publishing: Paris, France, 2004. 
38. Guilhermino, L.; Diamantino, T.; Silva, M.C.; Soares, A. Acute toxicity test with Daphnia magna: An alternative to mammals in the prescreening of chemical toxicity? Ecotoxicol. Environ. Saf. 2000, 46, 357-362. [CrossRef] [PubMed]

39. Tarrahi, R.; Mahjouri, S.; Khataee, A. A review on in vivo and in vitro nanotoxicological studies in plants: A headlight for future targets. Ecotoxicol. Environ. Saf. 2021, 208, 111697. [CrossRef]

40. Mkandawire, M.; Teixeira da Silva, J.A.; Dudel, E.G. The Lemna bioassay: Contemporary issues as the most standardized plant bioassay for aquatic ecotoxicology. Crit. Rev. Env. Sci. Technol. 2014, 44, 154-197. [CrossRef]

41. Patterson, A. The Scherrer formula for X-ray particle size determination. Phys. Rev. 1939, 56, 978. [CrossRef]

42. Arefi-Oskoui, S.; Vatanpour, V.; Khataee, A. Development of a novel high-flux PVDF-based ultrafiltration membrane by embedding Mg-Al nanolayered double hydroxide. J. Ind. Eng. Chem. 2016, 41, 23-32. [CrossRef]

43. Zeng, R.-C.; Li, X.-T.; Liu, Z.-G.; Zhang, F.; Li, S.-Q.; Cui, H.-Z. Corrosion resistance of Zn-Al layered double hydroxide/poly (lactic acid) composite coating on magnesium alloy AZ31. Front. Mater. Sci. China 2015, 9, 355-365. [CrossRef]

44. Motlagh, P.Y.; Khataee, A.; Hassani, A.; Rad, T.S. ZnFe-LDH/GO nanocomposite coated on the glass support as a highly efficient catalyst for visible light photodegradation of an emerging pollutant. J. Mol. Liq. 2020, 302, 112532. [CrossRef]

45. Rahmanian, O.; Amini, S.; Dinari, M. Preparation of zinc/iron layered double hydroxide intercalated by citrate anion for capturing Lead (II) from aqueous solution. J. Mol. Liq. 2018, 256, 9-15. [CrossRef]

46. Bundschuh, M.; Filser, J.; Lüderwald, S.; McKee, M.S.; Metreveli, G.; Schaumann, G.E.; Schulz, R.; Wagner, S. Nanoparticles in the environment: Where do we come from, where do we go to? Environ. Sci. Eur. 2018, 30, 1-17. [CrossRef] [PubMed]

47. Dabrunz, A.; Duester, L.; Prasse, C.; Seitz, F.; Rosenfeldt, R.; Schilde, C.; Schaumann, G.E.; Schulz, R. Biological surface coating and molting inhibition as mechanisms of $\mathrm{TiO}_{2}$ nanoparticle toxicity in Daphnia magna. PLoS ONE 2011, 6, e20112. [CrossRef]

48. Kahru, A. Ecotoxicological tests in non-ecotoxicological research: Contribution to the three Rs. ALTEX-HEIDELBERG 2006, 1, 302-308.

49. Bulich, A.A. A practical and reliable method for monitoring the toxicity of aquatic samples. Process Biochem. 1982, $17,45-47$.

50. Hastings, J.W.; Makemson, J.; Dunlap, P.V. How are growth and luminescence regulated independently in light organ symbionts? Symbiosis 1987, 4, 3-24.

51. Rossetto, A.L.D.F.; Melegari, S.P.; Ouriques, L.C.; Matias, W.G. Comparative evaluation of acute and chronic toxicities of CuO nanoparticles and bulk using Daphnia magna and Vibrio fischeri. Sci. Total Environ. 2014, 490, 807-814. [CrossRef]

52. Chen, F.; Wu, L.; Xiao, X.; Rong, L.; Li, M.; Zou, X. Mixture toxicity of zinc oxide nanoparticle and chemicals with different mode of action upon Vibrio fischeri. Environ. Sci. Eur. 2020, 32, 1-10. [CrossRef]

53. Kurvet, I.; Juganson, K.; Vija, H.; Sihtmäe, M.; Blinova, I.; Syvertsen-Wiig, G.; Kahru, A. Toxicity of nine (doped) rare earth metal oxides and respective individual metals to aquatic microorganisms Vibrio fischeri and Tetrahymena thermophila. Materials 2017, 10, 754. [CrossRef]

54. Sorokina, E.; Yudina, T.; Bubnov, I.; Danilov, V. Assessment of iron toxicity using a luminescent bacterial test with an Escherichia coli recombinant strain. Microbiology 2013, 82, 439-444. [CrossRef]

55. Déniel, M.; Errien, N.; Daniel, P.; Caruso, A.; Lagarde, F. Current methods to monitor microalgae-nanoparticle interaction and associated effects. Aquat. Toxicol. 2019, 217, 105311. [CrossRef] [PubMed]

56. Aruoja, V.; Dubourguier, H.-C.; Kasemets, K.; Kahru, A. Toxicity of nanoparticles of $\mathrm{CuO}, \mathrm{ZnO}$ and $\mathrm{TiO}_{2}$ to microalgae Pseudokirchneriella subcapitata. Sci. Total Environ. 2009, 407, 1461-1468. [CrossRef] [PubMed]

57. Franklin, N.M.; Rogers, N.J.; Apte, S.C.; Batley, G.E.; Gadd, G.E.; Casey, P.S. Comparative toxicity of nanoparticulate ZnO, bulk $\mathrm{ZnO}$, and $\mathrm{ZnCl}_{2}$ to a freshwater microalga (Pseudokirchneriella subcapitata): The importance of particle solubility. Environ. Sci. Technol. 2007, 41, 8484-8490. [CrossRef] [PubMed]

58. Ding, T.; Lin, K.; Chen, J.; Hu, Q.; Yang, B.; Li, J.; Gan, J. Causes and mechanisms on the toxicity of layered double hydroxide (LDH) to green algae Scenedesmus quadricauda. Sci. Total Environ. 2018, 635, 1004-1011. [CrossRef] [PubMed]

59. Bacchetta, R.; Maran, B.; Marelli, M.; Santo, N.; Tremolada, P. Role of soluble zinc in ZnO nanoparticle cytotoxicity in Daphnia magna: A morphological approach. Environ. Res. 2016, 148, 376-385. [CrossRef] [PubMed]

60. Blinova, I.; Ivask, A.; Heinlaan, M.; Mortimer, M.; Kahru, A. Ecotoxicity of nanoparticles of CuO and ZnO in natural water. Environ. Pollut. 2010, 158, 41-47. [CrossRef] [PubMed]

61. Baumann, J.; Köser, J.; Arndt, D.; Filser, J. The coating makes the difference: Acute effects of iron oxide nanoparticles on Daphnia magna. Sci. Total Environ. 2014, 484, 176-184. [CrossRef]

62. International Organization for Standardization (ISO). Water Quality_Determination of the Growth Inhibition Effects of Wastewaters, Natural Waters and Chemicals on the Duckweed Spirodela Polyrhiza-Method Using a Stock Culture Independent Microbiotest; 20227; International Organisation for Standardization: Geneva, Switzerland, 2017.

63. International Organization for Standardization (ISO). Water Quality Determination of the Inhibitory Effect of Water Samples on the Light Emission of Vibrio Fischeri (Luminescent Bacteria Test) Part 3: Method Using Freeze-Dried Bacteria; 11348-3; International Organisation for Standardization: Geneva, Switzerland, 2008.

64. International Organization for Standardization (ISO). Water Quality Freshwater Algal Growth Inhibition Test with Unicellular Green Algae; 8692; International Organisation for Standardization: Geneva, Switzerland, 2012.

65. Daphtoxkit, F ${ }^{\mathrm{TM}}$ magna. Crustacean Toxicity Screening Test for Freshwater. Standard Operational Procedure; Creasel: Deinze, Belgium, 1996.

66. Available online: https:/ / imagej.net/Citing (accessed on 1 February 2020). 